\title{
Art and Science Collaborate to Face the COVID-19 Pandemic
}

\author{
Sandra Ramos ${ }^{1}$, José de la Fuente 2,3* $^{*}$ \\ ${ }^{1}$ Sandra Ramos Art Projects LLC, 100 Bayview Drive apt. 1706, Sunny Isles Beach, Fl 33160, USA. \\ ${ }^{2}$ SaBio. Instituto de Investigación en Recursos Cinegéticos IREC-CSIC-UCLM-JCCM, Ronda de Toledo s/n, \\ 13005 Ciudad Real, Spain. \\ ${ }^{3}$ Department of Veterinary Pathobiology, Center for Veterinary Health Sciences, Oklahoma State University, \\ Stillwater, OK 74078, USA.
}

*Corresponding Author: José de la Fuente, SaBio. Instituto de Investigación en Recursos Cinegéticos IREC-CSIC-UCLM-JCCM, Ronda de Toledo s/n, 13005 Ciudad Real, Spain

\begin{abstract}
Debate about the interactions and collaboration between artists and scientists to advance science is relevant to the scientific community and the society in general. The COVID-19 pandemic constitutes a challenge for science and society. To further illustrate the possibilities offered by the collaboration between art and science, herein we resume artist's and scientist's view on pieces created by the artist during the pandemic. Art served to communication and education of the effect of the pandemic. However, the collaboration between artist and scientist also facilitated to approach questions posed by this emerging disease that contribute to mitigate the effects of the disease while advancing research to control COVID-19 and other infectious diseases. This study encourages a methodological approach that may be applied to address different scientific and social challenges.
\end{abstract}

Key Words: Science; Visual art; COVID-19; Action; Collaboration; Education

\section{InTRoduction: COLlaboration BetWEen ART AND SCIENCE}

The COVID-19 pandemic constitutes a challenge for science and society with an impact on human health and global economy. The debate on how the collaboration between artists and scientists may advance research and the social impact of science is relevant to the scientific community and the society in general. While art has been used to communicate and educate on the effect of the pandemic and the way to face and mitigate these effects [1], the collaboration between artists and scientists has served to approach scientific and social questions posed by this pandemic [2, 3].

The collaboration between visual art and science has promoted innovative approaches to address scientific challenges in different areas $[2,4,5]$. The results derived from these collaborations not only serve for communication and education [1,3], but also encourage and support the development of new methodological approaches to inspire scientists viewing previously unexplored properties when addressing scientific challenges $[2,4,5]$.

To further illustrate the possibilities offered by the collaboration between art and science, here we resume artist's and scientist's views on pieces created by the artist during the pandemic.

\section{ArTist VieW}

This series of drawings have functioned as cathartic self-therapy in the face of the isolation imposed by the COVID-19 pandemic. The drawings are small and spontaneous daily plastic discharges, liberation of moods and emotional energies through the use of collage, watercolor, charcoal and pastel (Fig. 1). These drawings express artist's personal reaction to uncertainty and social estrangement. In them, in addition to the personal and contextual references, there are poetic, philosophical and scientific allusions. In the series, the artist establishes a link between the ancient oriental concept of the Tao, and contemporary cosmologies where astronomy confirms the constant relationship between all the energies and materials of the universe. The pieces visually go from a microscopic to a macroscopic vision, one where we can be looking at a cell as well as a galaxy. The general idea is that all living beings, viruses, animals, humans, and inanimate matter, stones, earth, water, share a destiny 
interrelated with the creative and destructive forces of nature that always return us to the infinite dust of the universe.

A

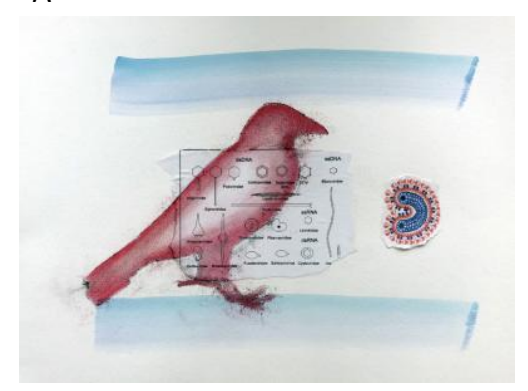

C

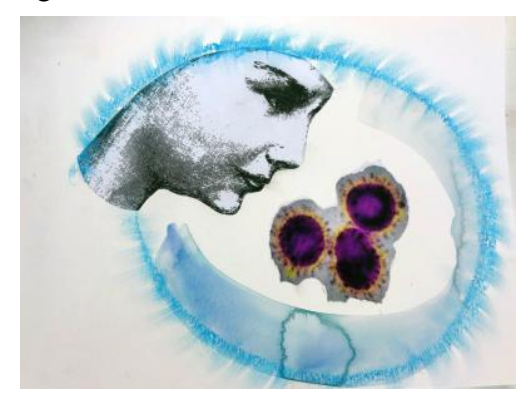

$E$

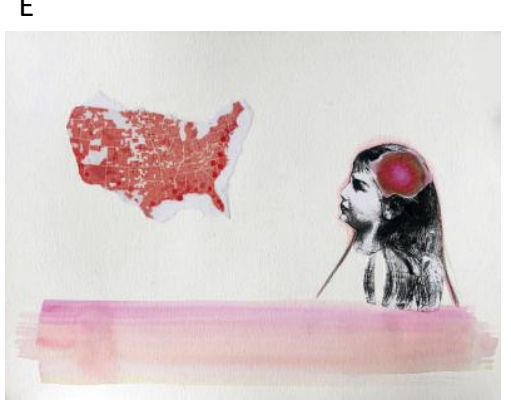

B

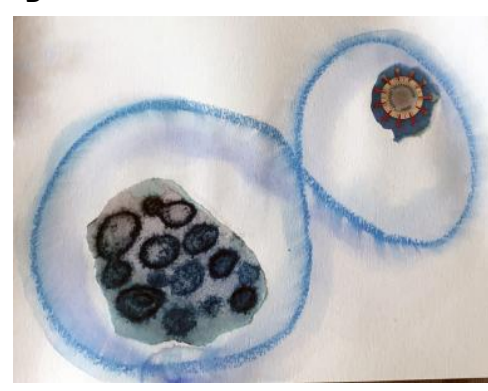

D

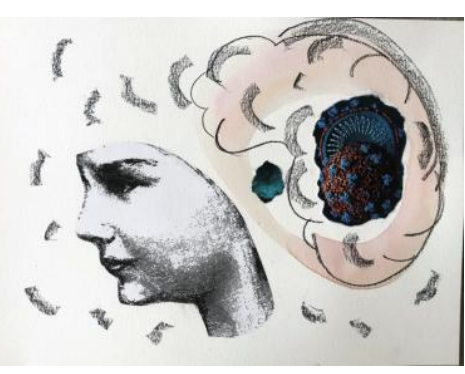

$\mathrm{F}$

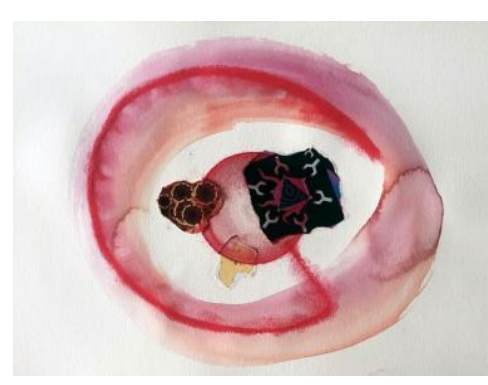

Figure1. Series Quarantined Drawings. The invisible karma. By Sandra Ramos. Size 11" x 15" each. Watercolor, collage and pastel on paper, 2020.

\section{SCIENTIST VIEW}

The biology of the coronavirus SARS-CoV-2 is represented in pieces A and B (Fig. 1). While the origin of the virus is still controversial [6], understanding the role of animal hosts of coronaviruses is important to control this and future pandemics [7,8]. Coronavirus infection and disease constitute a scientific challenge still under investigation. While the main route of SARS-CoV-2 infection and transmission is through the respiratory tract in person-to-person close contact and respiratory droplets (Fig. 1, piece C), the virus can infect multiple organs such as brain with different disease symptoms (Fig. 1, piece D) [9]. A global One Health approach is required for control of COVID-19 and prevention of future pandemics (Fig. 1, pieces E and F). A One Health perspective by combining research on environmental and epidemiological factors, virus animal hosts and transmission routes, and virus-host molecular interactions through collaboration between science and society with a balanced interaction of humanity with nature and a more holistic approach to disease control is necessary for a more effective prevention of current and future pandemics.

\section{CONCLUSION}

The interaction and collaboration between art and science summarizes "ation" terms or the action or process of doing something such as inspiration, complementation, diversification, communication, innovation, and experimentation. The collaboration between art and science could be implemented using multiple approaches (e.g., [10]). 
In this example case, while the artist perceived the pandemic with personal references to science, the scientist was inspired by these pieces to pose and address scientific questions such as (a) are known and unknown animal hosts with low or high susceptibility to SARS-CoV-2 a risk factor for the appearance of new variants? [8, 11-14], (b) how the coronavirus infects brain and other organs in some individuals? [9, 15], and (c) is it possible to develop algorithms to evaluate the disease risks and predict future pandemics? [16-18]. Answering these questions that arise from this art-science collaboration will contribute to the prevention and control of COVID-19 and other emerging infectious diseases. This example study encourages a methodological approach that may be applied to address different scientific and social challenges.

\section{REFERENCES}

[1] Stower, H., \&Guennot, M. (2021). Art in a pandemic: a digital gallery. Nature Medicine, 10.1038/d41591021-00009-5.

[2] 2. de la Fuente, J. (2020). The exquisite corpse for the advance of science. Art and Science, 4, 43. https://www.openscience.fr/The-exquisite-corpse-for-the-advance-of-science

[3] 3. de la Fuente, J., Bedia, J., \&Gortázar, C. (2020a). Visual communication and learning from COVID-19 to advance preparedness for pandemics. Exploration of Medicine, 1, 244-247.

[4] Eldred, S.M. (2016). Art-science collaborations: Change of perspective. Nature, 537, 125-126.

[5] Artigas-Jerónimo, S., Comín, J., Villar, M., Contreras, M., Alberdi, P., Viera, I. L., Soto, L., Cordero, R., Valdés, J. J., Cabezas-Cruz, A., Estrada-Peña, A., \& Fuente, J. (2020). A Novel Combined Scientific and Artistic Approach for the Advanced Characterization of Interactomes: The Akirin/Subolesin Model. Vaccines, 8, 77.

[6] Bloom, J. D., Chan, Y. A., Baric, R. S., Bjorkman, P. J., Cobey, S., Deverman, B. E., Fisman, D. N., Gupta, R., Iwasaki, A., Lipsitch, M., Medzhitov, R., Neher, R. A., Nielsen, R., Patterson, N., Stearns, T., van Nimwegen, E., Worobey, M., \&Relman, D. A. (2021). Investigate the origins of COVID19. Science, 372, 694.

[7] Sharun, K., Dhama, K., Pawde, A. M., Gortázar, C., Tiwari, R., Bonilla-Aldana, D. K., RodriguezMorales, A. J., de la Fuente, J., Michalak, I., \&Attia, Y. A. (2021). SARS-CoV-2 in animals: potential for unknown reservoir hosts and public health implications. The Veterinary Quarterly, 41, 181-201.

[8] Wardeh, M., Blagrove, M.S.C., Sharkey, K.J., \& Baylis, M. (2021). Divide-and-conquer: machinelearning integrates mammalian and viral traits with network features to predict virus-mammal associations. Nature Communications, 12, 3954.

[9] Trypsteen, W., Van Cleemput, J., Snippenberg, W. V., Gerlo, S., \&Vandekerckhove, L. (2020). On the whereabouts of SARS-CoV-2 in the human body: A systematic review. PLoSPathogens, 16, e1009037.

[10] de la Fuente, J., Artigas-Jerónimo, S., \& Pastor Comín, J.J. (2020b). Collaboration between scientists and artists: a research methodological approach to advance science. Merit Research Journal of Microbiology and Biological Sciences, 8, 41-46. https://www.meritresearchjournals.org/mbs/content/2020/November/ Fuente\%20et\%20al.pdf

[11] Oude Munnink, B. B., Sikkema, R. S., Nieuwenhuijse, D. F., Molenaar, R. J., Munger, E., Molenkamp, R., van der Spek, A., Tolsma, P., Rietveld, A., Brouwer, M., Bouwmeester-Vincken, N., Harders, F., Hakzevan der Honing, R., Wegdam-Blans, M., Bouwstra, R. J., GeurtsvanKessel, C., van der Eijk, A. A., Velkers, F. C., Smit, L., Stegeman, A., ... Koopmans, M. (2021). Transmission of SARS-CoV-2 on mink farms between humans and mink and back to humans. Science, 371, 172-177.

[12] Banerjee, A., Mossman, K., \& Baker, M. L. (2021). Zooanthroponotic potential of SARS-CoV-2 and implications of reintroduction into human populations. Cell Host \& Microbe, 29, 160-164.

[13] Gortázar, C., Barroso-Arévalo, S., Ferreras-Colino, E., Isla, J., de la Fuente, G., Rivera, B., Domínguez, L., de la Fuente, J., \&Sánchez-Vizcaíno, J.M. (2021). Natural SARS-CoV-2 infection in kept ferrets, Spain. Emerging Infectious Diseases, in press. Preprint: bioRxiv2021.01.14.426652;doi: https://doi. org/10.1101/2021.01.14.426652

[14] Lam, S. D., Ashford, P., Díaz-Sánchez, S., Villar, M., Gortázar, C., de la Fuente, J., \&Orengo, C. (2021). Arthropod Ectoparasites Have Potential to Bind SARS-CoV-2 via ACE. Viruses, 13, 708.

[15] Urra, J. M., Ferreras-Colino, E., Contreras, M., Cabrera, C. M., Fernández de Mera, I. G., Villar, M., Cabezas-Cruz, A., Gortázar, C., \& de la Fuente, J. (2021). The antibody response to the glycan $\alpha$-Gal correlates with COVID-19 disease symptoms. Journal of Medical Virology, 93, 2065-2075. 
[16] Hodžić, A., de la Fuente, J., \& Cabezas-Cruz, A. (2020). COVID-19 in the Developing World: Is the Immune Response to $\alpha-\mathrm{Gal}$ an Overlooked Factor Mitigating the Severity of Infection?.ACS InfectiousDiseases, 6, 3104-3108.

[17] Loubet, P., Sotto, A., \& AVNIR group (2021). Covid-19 pandemic: an opportunity to seize to increase awareness and vaccine coverage in at-risk populations. Human Vaccines \& Immunotherapeutics, 1-2. Advance online publication. https://doi.org/10.1080/21645515.2021.1926760

[18] Wenham, C., Kavanagh, M., Torres, I., \&Yamey, G. (2021). Preparing for the next pandemic. BMJ (Clinicalresearch ed.), 373, n1295.

\section{AUTHORS' BIOGRAPHY}

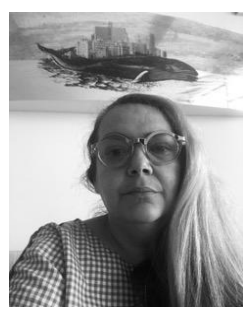

Sandra Ramos, is a Cuban visual artist with work acting as a bridge, a line that connects her ideas with those of others and with the past and the future of her country, a path to tolerance, difference, amazement before the world and its beauty, the virtue of innocence and love. She also contributes to collaborations for the advancement of society. In her work even the sadness can be a positive force and the distance a passing event.

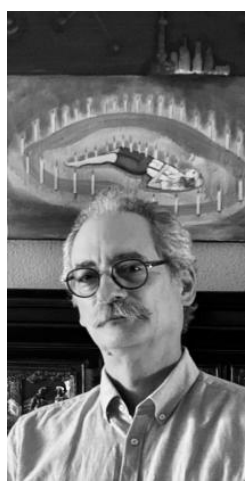

José de la Fuente, is a Physicist and currently a Professor of Molecular Biology and Biotechnology in the SaBio group at the IREC (CSIC-UCLMJCCM), Spain and the Oklahoma State University, USA. He is interested in innovative research approaches and his work focuses on systems biology of host-vector-pathogen molecular interactions, and translation of this basic information into development of effective vaccines and other interventions for the control of infectious diseases affecting human and animal health worldwide, ticks and tick-borne diseases, Alpha Gal Syndrome, Vaccinology and Quantum Vaccinomics.

Citation: Sandra Ramos, José de la Fuente. "Art and Science Collaborate to Face the COVID-19 Pandemic" International Journal of Humanities Social Sciences and Education (IJHSSE), vol 8, no. 7, 2021, pp. 267-270. doi: https://doi.org/10.20431/2349-0381.0807029.

Copyright: (C) 2021 Authors. This is an open-access article distributed under the terms of the Creative Commons Attribution License, which permits unrestricted use, distribution, and reproduction in any medium, provided the original author and source are credited. 